\title{
Time for honest debate and critical friends. Commentary on ... New Ways of Working ${ }^{\dagger}$
}

At the risk of sounding defensive, I preface this commentary by stating that I fully support what I believe to be the principles that underpin New Ways of Working. Also, I suspect that my views about the roles that psychiatrists might devolve to others lie at the more radical end of the spectrum. Having said that, I would challenge some of the inferences contained in the piece by Vize et al and would argue that we as a profession should be permitted to adopt a questioning approach to the implementation of the New Ways of Working policy.

\section{New is not always better and change is not always improvement}

Vize et al define New Ways of Working as being 'what it says - new ways of working'. I could accept this aphorism more easily had the initiative been christened 'Better Ways of Working'. As it is, the title weds the concept to change as if change was always desirable. It is not fashionable to defend the value of permanence but does constant change always benefit those users of mental health services who, because they have chronic disorders, wish to forge a lasting relationship with their care workers? Is it really desirable that the pace of change will be such 'that no team will be able to stay still in the midst of it all'? Will this encourage the development of the relationships, both personal and organisational, that are essential to integrated care and which presumably will be one of the factors that will influence whether a particular new way of working will succeed? Knowledgeable commentators have argued that, far from being beneficial, constant change can itself be a barrier to service improvement (Smith, Walshe \& Hunter, 1991).

\section{Let us agree what works and discard what doesn't}

Because not everything that is new is better, a proposed change brought in under the New Ways of Working banner should be examined critically, including for unforeseen adverse consequences, before being adopted universally in preference to the 'old way of working'. This is not to advocate that each development should be supported by evidence from randomised controlled trials but it should at least have been subject to objective evaluation. At a minimum, this might include whether it achieves its stated objective (for example, of increased productivity), whether it is acceptable to all concerned (for example, to patients or to those who refer patients into that part of the service) and whether there are any adverse consequences (for example, has patient safety been compromised in any way?)

\author{
New Ways of Working should be \\ promoted as a set of practical ideas \\ and not as a creed
}

Vize et al are leading the implementation of the programme and this perhaps explains the messianic tone of their editorial. However, they cannot expect that all will be as enthusiastic about the initiative as they are. Nor can they expect uncritical endorsement of a concept that is so ill-defined. We do not know where New Ways of Working will lead us and cannot be expected to simply follow in blind faith. Those who question specific aspects of the implementation of the programme must not be branded as apostates and denounced as non-believers

The rate-limiting factor might be the ability of other disciplines to take on new roles rather than the willingness of psychiatrists to give up existing roles

The reluctance of some psychiatrists to transfer existing roles to colleagues from other disciplines might be due to concerns that they are not equipped to take on these new tasks. Such fears should not be dismissed out of hand as defensiveness nor as an excuse for maintaining a closed shop. Although, as Vize et al say, the General Medical Council will not hold psychiatrists responsible for the care provided by other members of the team, it does expect that 'when you delegate care or treatment you must be satisfied that the person to whom you delegate has the qualifications, experience, knowledge and skills to provide the care or treatment involved' (General Medical Council, 2006, p. 26).

Although the key change envisaged by New Ways of Working relates to distributed responsibility - for which the employer takes responsibility, as opposed to delegated responsibility - for which the doctor is responsible, is there always a clear line between the two? For example, in a team where a social worker, in their capacity as a care coordinator, is expected to assess newly referred patients or to recognise medication side effects, are these responsibilities that can be distributed? If not, how does a consultant make the decision that the social worker is competent for these responsibilities to be delegated to them?

Vize et al are right in asserting that psychiatrists should not just embrace the principles that underpin New Ways of Working but should lead the process. However, those that are accountable to the Department of Health for the implementation of the policy must not be oversensitive to criticism and must be careful that healthy opinion \& debate 
opinion \& debate questioning and debate by psychiatrists is not used to create artificial schisms between the disciplines that work together in mental health.

\section{Declaration of interest}

None. The views expressed in this commentary are the author's own and not those of the Royal College of Psychiatrists.

\section{References}

GENERAL MEDICAL COUNCIL (2006)

Good Medical Practice. General

SMITH, J., WALSHE, K. \& HUNTER, D. J.

(2001) The 'redisorganisation' of the

NHS. BMJ, 323, 1262-1263.

Paul Lelliott Director, Royal College of Psychiatrists' Research and Training Unit, 21 Mansell Street, London E1 8AA, UK, email: plelliott@ cru.rcpsych.ac.uk 